\title{
IMAGENS DO CAMPONÊS NA PINTURA BRASILEIRA: OSERTANEJ O DE CARLOS CHAMBELLAND
}

\author{
Arthur Valle \\ Instituto Superior de Educação \\ Fundação de Apoio à Escola Técnica \\ artus_agv@yahoo.com.br
}

\section{Resumo}

Após uma temporada no Estado de Pernambuco, o pintor e ilustrador fluminense Carlos Chambelland (1884-1950), julgando ter ali encontrado a própria essência da cultura brasileira, começou a produzir uma série de quadros que figuravam os tipos humanos do sertão nordestino, os seus modos de vida e o seu ambiente. No presente artigo, procurando compreender melhor esses quadros 'sertanejos' de Chambelland, analisamos como eles dialogaram com as tendências regionalistas que marcaram as artes plásticas brasileiras desde meados do século XIX e se inseriram no debate mais amplo a respeito da identidade cultural brasileira, uma das preocupações proeminentes nos círculos intelectuais da Primeira República.

Palavras-chave: Carlos Chambeland; Sertanejo; Identidade Cultural Brasileira; Pintura na Primeira República

Images of the peasant in the Brazilian painting: sertanejo of Carlos Chambelland

\begin{abstract}
After a season in the State of Pernambuco, the painter and illustrator Carlos Chambelland (1884-1950), judging to have finded the true essence of the Brazilian culture, began to produce a series of pictures that figured the human types of the northeastern hinterland, its ways of life and environment. In the present article, trying to better understand these pictures of Chambelland, we analyze their dialog with the regionalist trends that marked the Brazilian visual arts since the mid-19 $9^{\text {th }}$ century XIX and how they were inserted in the debates concerning the Brazilian cultural identity, one of the prominent concerns in the intellectual circles of the so-called First Republic.
\end{abstract}

Keywords: Carlos Chambeland; Sertanejo; Brazilian cultural identity; Painting in the First Republic 
Em uma entrevista concedida ao jornalista e historiador João Angyone Costa, publicada originalmente em uma edição dominical do periódico fluminense $O \mathrm{Jor}$ nal, em 22 de agosto de $1926^{1}$, e depois reeditada no famoso livro A Inquietação das Abelhas, de 1927, o pintor e ilustrador Carlos Chambelland foi questionado a respeito dos rumos que a arte brasileira deveria naquele momento tomar. O clima cultural no Brasil era dos mais agitados: o pacto oligárquico que governara o país durante todo o primeiro período republicano dava claros sinais de esgotamento, anunciando o advento de uma nova configuração política que se concretizaria com o Estado Novo. Poucos anos antes, em 1922, realizara-se, no Teatro Municipal de São Paulo, a famosa Semana de Arte Moderna, que reivindicava, com estardalhaço, uma arte genuinamente brasileira, regida por novos padrões estéticos que contemplassem aquilo que de típico havia em nosso país.

Como o problema da identidade cultural brasileira se apresentava com uma urgência renovada também no meio artístico do Rio de Janeiro, não é de se espantar que Chambelland expressasse a sua opinião a respeito dos possíveis novos rumos artísticos com a firmeza digna de um manifesto. Vale a pena reproduzir aqui, na íntegra, as palavras que então endereçou a Angyone Costa a esse respeito:

A orientação do pintor brasileiro, que pense commigo, nesse ponto, tem de ser a procura do convívio da gente do Norte, onde senti, - eu que sou carioca, aqui sempre vivi, e só sahi duas vezes para a Europa - o verdadeiro espírito da nacionalidade, o orgulho de ter nascido aqui. O Rio e o sul do país estão muito trabalhados pela influencia estrangeira, o cosmopolitismo absorveu-nos tanto, que hoje, sómente no norte, se nos depara, em sua pureza inicial, o sentimento da pátria aferrado á tradição, aos costumes, á vibração da alma do povo. Acredite, pela primeira vez envaedeci-me da minha nacionalidade, quando vivi tres annos - os melhores da minha vida em Pernambuco, recebido com um carinho, com um affecto, que não são muito communs por aqui, no seio daquella gente, amiga e bôa, que se excede na propria gentileza para agradar o hospede. ${ }^{2}$

Essa estadia de Chambelland no Nordeste, onde o "genio bom do povo" o fizera "conhecer a terra e começar a amar fortemente o Brasil"', forneceu-lhe igualmente a inspiração para que ele desse início à produção de uma série de telas abordando tipos e cenas sertanejas, como Depois da feira, Vaqueiro e Volta do trabalho [Figura 1], que constituem o fio condutor do nosso presente artigo e que são bastante representativas das preocupações nacionalistas que marcaram uma boa parte de nossa intelectualidade desde os tempos do Brasil Império. 


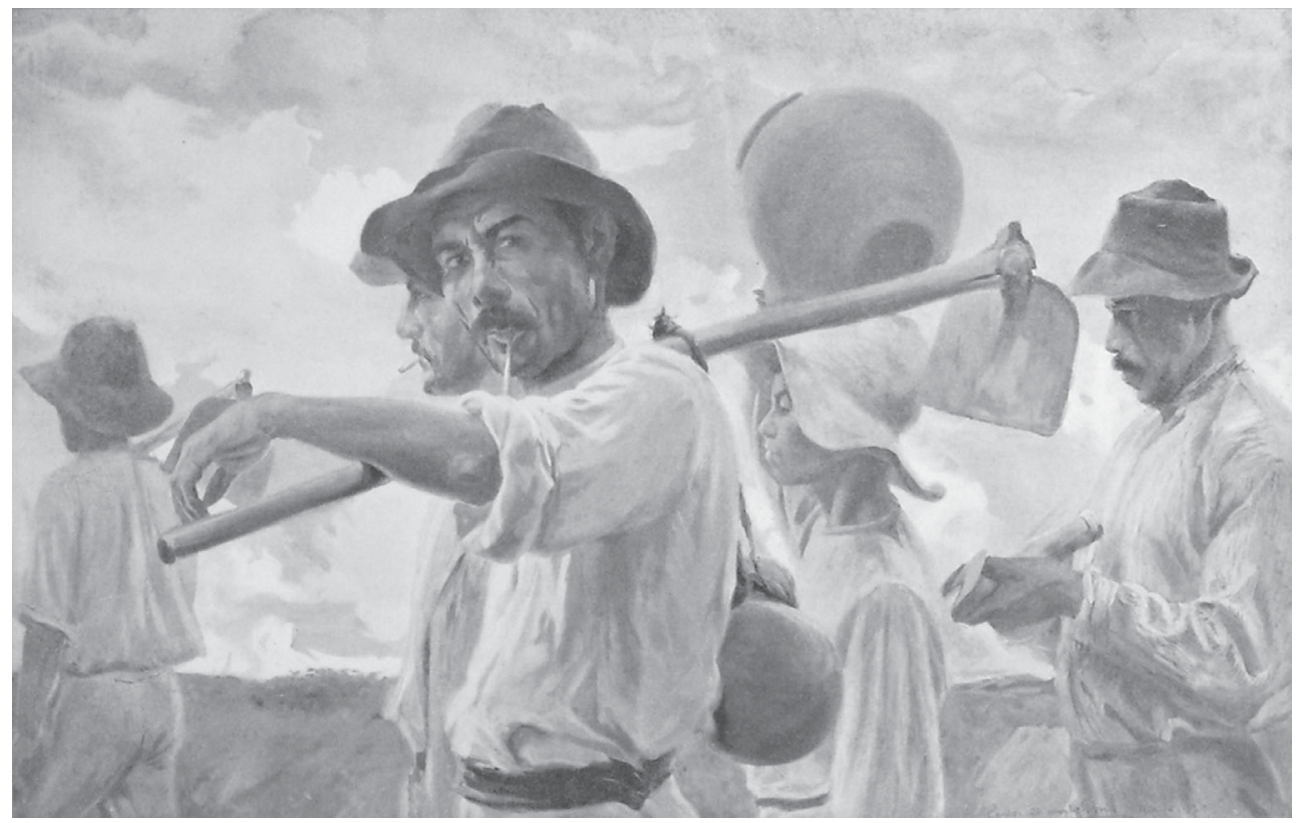

Figura 1 - CARLOS CHAMBELLAND: Volta do trabalho, s.d. Óleo sobre tela, $150 \times 95 \mathrm{~cm}$.

Fonte: ACQUARONE, Francisco; VIEIRA, Adão de Queiróz. Primores da Pintura no Brasil. Rio de Janeiro, 1941, n.p.

Muito provavelmente, a estadia de Chambelland em Pernambuco se deveu a motivos profissionais. Nesse sentido, segundo José Roberto Teixeira Leite, o pintor teria sido então incumbido, no Recife, da decoração da Igreja das Graças e do Colégio da Estância ${ }^{4}$. Todavia, como acontece com relação a tantos outros fatos que dizem respeito aos nossos artistas da Primeira República, os detalhes sobre essa temporada de Chambelland no Nordeste são ainda obscuros. Em um outro trecho da entrevista acima citada, o próprio artista fez uma breve referência à sua ida para Pernambuco: "Voltei novamente à Europa, com outros colegas, incumbido da decoração do pavilhão de Turim [...] Regressando ao Brasil, fui a Pernambuco"5. Sabemos que essa estadia na Europa de Chambelland - na verdade, a sua segunda ${ }^{6}$ - ocorrera por volta de 1911, data da realização da Exposição Internacional de Turim: 1911 marca, portanto, uma data limite, antes da qual, certamente, não ocorreu a temporada de Chambelland no Nordeste. Porém, em nossas pesquisas até agora realizadas, só muito depois de 1911 pudemos encontrar referências explícitas a quadros de Chambelland abordando a temática sertaneja. Vale lembrar, por exemplo, que, em finais de 1917, o artista realizou uma 
mostra individual na cidade de São Paulo, que foi resenhada pelo articulista N. provavelmente Nestor Pestana - em um elogiosa crítica publicada na Revista do Brasil $^{7}$. É significativo que, em tal resenha, não conste qualquer referência a obras retratando tipos brasileiros - o que certamente não seria o caso se elas lá estivessem, uma vez que não teriam passado desapercebidas aos responsáveis pelo períodico, caracterizado então por aquilo que Tadeu Chiarelli definiu como um verdadeiro "nacionalismo militante"8. Se não é propriamente um indício conclusivo, essa suposta ausência de pinturas 'sertanejas' na exposição de Chambelland em São Paulo leva-nos a levantar a hipótese de que, mesmo que a estadia do pintor no Nordeste tenha ocorrido antes de 1917, somente após essa data ele teria começado a pintar telas a ela relacionadas.

O fato é que só quando da Exposição Geral de Belas Artes de 1921 encontramos a referência a uma tela de Chambelland que, em seu título, remete inequivocamente à temporada nordestina do pintor: esta chamava-se Paisagem pernambucana e figurou sob o n.34, na seção de Pintura do famoso certame que era realizado anualmente no Rio de Janeiro. No ano seguinte, 1922 - data da já referida Semana de Arte Moderna - Chambelland voltaria a figurar na Exposição Geral com duas telas chamadas Dia de Feira (Seção Pintura, n.53) e Água Corrente (Seção Pintura, n.54). Pela proximidade do título da primeira dessas obras com o de outra tela - Depois da Feira -, reproduzida na edição d'O Jornal acima citada, podemos supor que também Dia de Feira figurasse um tema 'sertanejo'. Ainda reforçando a hipótese de que as telas de Chambelland expostas em 1922 faziam parte do ciclo inspirado na estadia pernambucana, se encontra o fato de que ambas eram propriedade de José Mariano Filho, ferrenho nacionalista e um dos principais articuladores do movimento Neo-Colonial em terras fluminenses. Sabemos, além disso, que, durante os anos 1920, Chambelland voltaria a mostrar algumas outras telas versando sobre os temas 'sertanejos’ nas Exposições Gerais, como Trapicheiro (Seção Pintura, n.87a), em 1927, e Sertanejo (Seção Pintura, n.42), em 1929 - obras das quais não encontramos, até o momento, registros fotográficos Provisoriamente, portanto, podemos afirmar apenas que a estadia de Chambelland em Pernambuco se deu entre a primeira metade dos anos 1910 e o começo da década de 1920 e que é posível que a produção de suas telas 'sertanejas' seja um tanto posterior à tal estadia - afirmações que são, certamente, insatisfatórias e demandam a continuidade das pesquisas. Todavia, pondo de lado por alguns momentos as incertezas a respeito da exata cronologia dos eventos que levaram o pintor a se interessar pelos motivos ambientados no Nordeste brasileiro, o certo é que Chambelland, assim fazendo, agiu como um pioneiro, inaugurando um novo filão iconográfico na arte brasileira. Em meados dos anos 1920, artistas de uma geração mais nova como Manoel 
Santiago, Raimundo Cela ou Cadmo Fausto, já apressavam-se em seguí-lo, buscando igualmente inspiração nos habitantes, nos modos de vida, na natureza e nas lendas do Nordeste e do Norte do país. Segundo Luiz Marques, inclusive, o caminho trilhado por Chambelland "não terá sido sem efeito sobre os fermentos regionalistas que levaram à eclosão, no início dos anos 1930, do assim chamado 'romance nordestino' de Lins do Rego e outros". Além disso, podemos dizer que, apesar de sua indubitável originalidade, o pensamento e as obras 'sertanejas' de Chambelland se vinculavam, em seus contornos mais gerais, a uma bem estabelecida tendência regionalista que permeava as artes plásticas brasileiras, de uma maneira mais ou menos intensa, desde meados do século XIX. Nas páginas que se seguem, gostaríamos primeiramente de esboçar a genealogia dessa tendência, para por fim concluirmos o artigo discutindo de que maneira ela ganhou uma configuração toda particular nas obras de Carlos Chambelland.

\section{O BRASILEIRO EM IMAGENS}

Como deixou entrever aquilo que acima adiantamos, o interesse pelos habitantes do sertão nordestino que Chambelland exprimia em suas pinturas não se devia a uma idiossincrasia pessoal. Ele se encontrava em sintonia com um esforço mais amplo de nossa intelectualidade, derivado de uma necessidade que se tornou particularmente urgente após a proclamação da República: a de elaborar mecanismos simbólicos eficazes para a consolidação da identidade e da unidade brasileiras. Mas o fato é que esse esforço de construção de uma identidade nacional era ainda mais antigo, tendo permeado, sem solução de continuidade, boa parte da nossa produção cultural desde meados do século XIX. Os precedentes mais antigos da tentativa de elevar um tipo brasileiro à categoria de encarnação da ansiada identidade nacional podem ser encontrados no culto indianista romântico, que marcou as mais diversas artes durante o II Reinado, e cujos exemplos talvez mais típicos podem ser encontrados na literatura de Gonçalves Dias e José de Alencar, ou na música de Carlos Gomes.

A opção romântica pelo indígena como símbolo do Brasil teve também, como não poderia deixar de ser, uma grande penetração nas artes plásticas. A partir da década de 1860, em pinturas como A Primeira Missa no Brasil (1860), de Victor Meirelles, ou em esculturas como Indío simbolizando a nação brasileira (1872), de Chaves Pinheiro, o indígena de semblante idealizado emerge como modelo de representação do país. Como sublinhou Lilia Moritz Schwarcz a esse respeito, a figura do índio era

a melhor resposta para uma elite que se perguntava incessantemente sobre sua identidade, sobre sua verdadeira singularidade. Diante da rejeição ao negro escravo e mesmo ao branco 
colonizador, o indígena restava como uma espécie de representante digno e legítimo. "Puros, bons, honestos e corajosos", os índios atuavam como reis no exuberante cenário da selva brasileira e em total harmonia com ela. ${ }^{10}$

Todavia, a partir da conturbada década de 1880 - e apesar de exemplos de tais representações mitificadas continuarem a ser produzidas, como testemunham telas como Iracema (1881), de José Maria de Medeiros -, o recurso à figura idealizada do índio como símbolo de identidade brasileira ia aos poucos exaurindo as suas forças. Criticada pelos intelectuais ligados ao Realismo e pelos boêmios, ironizada na imprensa por figuras como Angelo Agostini, a exaltação romântica do exótico entrava em crise. Um claro exemplo pictórico desse esgotamento é a tela $O$ último Tamoyo (1883) de Rodolpho Amoêdo, marcada por um tom patético e derrisório, que levou Luciano Migliaccio a classificá-la como "o último grande quadro indigenista possível no Brasil. Depois, o índio torna-se figurante de ilustração histórica" 11 .

Uma das alternativas ao índio como símbolo do nação que se fixaram na mente dos intelectuais e artistas brasileiros ainda antes do fim do período imperial foi a figura do homem do campo, do qual o sertanejo, explorado por Chambelland em suas obras já adentrado o século XX, constituía, em certa medida, uma variante particular.

$\mathrm{Na}$ época, porém, essa escolha do camponês como emblema da nação não fora, obviamente, uma invenção brasileira. Na Europa, fazendo eco de maneira mais ou menos explícita às idéias desenvolvidas por filósofos como J. G. von Herder, que exaltavam o camponês e a cultura popular como evidência de um tipo de criatividade inata, muitos identificaram nos hábitos simples do camponês uma expressão de vida mais natural e pura, em contraste com a decadência e a artificialidade das sociedades ocidentais urbanas. O mito do homem do campo como uma figura de grande valor moral e a exortação aos habitantes das grandes cidades a se tornarem melhores através do contato com a vida rústica - temas que ecoam claramente nas palavras de Chambelland que reproduzimos no início desse artigo -, revelam como a imagem do camponês foi manipulada pelo habitantes dos grandes centros urbanos europeus. Refletindo tais concepções, o camponês passa a figurar com destaque na pintura de artistas dos mais diversos países europeus e as suas primeiras representaçãoes na pintura brasileira surgem, assim, como o fruto do estreito diálogo que nossos artistas mantinham com a cultura figurativa do Velho Mundo. Cremos que uma breve consideração a respeito desse tópico é interessante para que possamos melhor entender as razões por tais da escolha do sertanejo por parte de Carlos Chambelland. 
Imagens do camponês na pintura brasileira: o sertanejo de Carlos

Chambelland

\section{IMAGENS DO HOMEM RURAL - I: O CAMPONÊS EUROPEU VISTO PELOS ARTISTAS BRASILEIROS}

É bem antiga e conhecida a tradição do pastoralismo nas artes ocidentais. $\mathrm{Na}$ literatura, por exemplo, desde antes das Geórgicas de Virgílio, a alma e a vida camponesa constituíam o tema central de uma produção artística abundante, especialmente em épocas de crescimento urbano. De modo geral, pode-se dizer que desde então os artistas se preocupavam menos em retratar fielmente a modos de vida e a mentalidade camponesa do que exprimir o sentimento a respeito das mesmas nutrido pela sua clientela, as elites urbanas européias: se o homem cultivado da cidade se detinha sobre o camponês era por acreditar nele encontrar valores que o fascinavam, precisamente por serem a antítese de seu próprio modo de vida ${ }^{12}$.

Na pintura, é sobretudo a partir do século XIX que os aspectos do cotidiano rural asumem uma importância decisiva na produção de artistas urbanos. Embora alguns quadros importantes e inúmeras gravuras e estudos de camponeses tivessem antecedido tal surto, datam das primeiras décadas do oitocentos os programas artísticos que deliberadamente procuravam conferir aos temas camponeses uma importância equivalente a que então conheciam os do repertório clássico - ou seja, os temas históricos, mitológicos ou religiosos -, que, desde finais do século XVIII, conheciam um sensível esgotamento.

Em um seu livro dedicado a imagem do camponês no século XIX, Richard e Caroline Brettell chamaram a atenção para uma verdadeira avant-garde do gênero 'camponês', formada por artistas franceses estabelecidos na Itália e cujas obras hoje vem sendo recuperadas, como Léopold Robert, Jean Victor-Schnetz, Achille Michallon e Hortense Haudebourt-Lescot, os quais, a partir do começo dos anos 1820, exaltavam, em imagens idealizadas e ancoradas em uma estética que muito devia à tradição clássica pós-renascentista, o camponês italiano como um autêntico descendente dos romanos da Antiguidade, como uma figura 'fora do tempo', pertencente ao mundo do trabalho rural ritmado pelas estações ${ }^{13}$. Mais ou menos na mesma época, os anos 20 e 30 do século XIX, artistas alemães como Johann Friedrich Overbeck ou Erwin Speckter também se voltaram para os tipos campesinos da península italiana, que retratavam lançando mão de uma sintaxe pictórica ainda mais estilizada do que a de seus congêneres franceses. Essas visões classicizantes dos habitantes do campo conheceram um grande suceso nos Salons parisienses do início da década de $1830^{14}$ e seus ecos podem ser percebidos mesmo quando o século já ia bem adiantado, nos famosos capriccios de Jean-Baptiste Camille Corot ou, especialmente, nas telas de William Bougeureau e de alguns outros artistas de muito sucesso na segunda metade do oitocentos. Mais ou menos nessa mesma época, todavia, uma reação 'realis- 
ta' viria a se opor às idealizações artísticas do camponês e dos seus modos de vida. Fazendo eco ao grande desenvolvimento que a Antropologia, as Ciências Sociais e os estudos de folklore conheceram na Europa da segunda metade do oitocentos, inúmeros pintores e gravadores se consagraram então a uma descrição supostamente fiel dos costumes camponeses nas diferentes regiões da Europa. Foi o caso, na França, do célebre Gustave Courbet, de Jules Breton e de Jean-François Millet; na Alemanha, de Ferdinand Waldmüller, Wilhelm Leibl e Max Liebermann; na Noruega, de Adolph Tidemand; na Itália, dos irmãos Palizzi, de Francesco Paolo Michetti, e de tantos outros mais.

Aqui é importante fazer referência a esse impulso quase 'etnógrafico', que tendo suas raízes nos estudos dos Nazarenos alemães e dos Puristas italianos ${ }^{15}$, reverberou diretamente na cultura figurativa brasileira. Quando de suas estadias de estudos na Itália, artistas como Manoel de Araújo Porto-alegre e Victor Meirelles se dedicaram ao registro atento dos tipos da campagna. É especialmente notável, nesse sentido, a extensa série de tipos italianos aquarelados por Meirelles em meados dos anos 1850, boa parte da qual hoje conservada no Museu Nacional de Belas Artes do Rio de Janeiro, e onde o pintor, se afastando da sedução pitoresca, "produz admiráveis imagens, que partem de uma cuidada observação, mas que se resolvem, estritas, concentradas, despojadas, com escolhas plásticas incisivas e simplificadas, numa concepção sintética que as fixa, de modo grave, icônico" ${ }^{16}$. Porém, trabalhos como os de Porto-Alegre ou de Meirelles, repletos de verossimilhança, eram apenas estudos reservados ao uso privado desses pintores, e não obras acabadas. É somente a partir de finais da década 1870 que podemos encontrar quadros de artistas brasileiros versando sobre temas camponeses que, por seu refinado grau de finalização técnica e por sua destinação pública, elevaram o gênero a um novo patamar. Não por acaso, foi novamente na obra de pintores que então complementavam as suas formações artísticas na Europa, como Henrique Bernardelli, Pedro Weingärtner ou Belmiro de Almeida, que esse estatuto mais elevado das representações do homem do campo e de seus costumes ganhou um incremento notável.

Telas de Bernardelli como Cabeça de Carroceiro, Cabeça de Ciccioro, Ao Sol ou sua célebre representação da Tarantella, dança símbolo da cultura napolitana, foram expostas nos Rio de Janeiro nos anos 1880 e receberam francos elogios por parte dos mais conhecidos críticos de arte brasileiros do período, como Gonzaga Duque e Oscar Guanabarino, não somente pela sua temática, mas também pela técnica empregada, com seu realismo e suas fatura vigorosa. Apresentando um registro estilístico diverso, mas igualmente elogiadas pela crítica brasileira de fins do oitocentos, foram as pinturas de temas campesinos feitas por Belmiro da Almeida, em quadros como Idílio Campestre ou Efeitos de Sol, nos 
quais os típicos habitantes da campagna eram figurados como uma técnica próxima do Divisionismo comum na obra de pintores italianos como Pelizza de Volpedo e Giovanni Segantini. A relativa 'opacidade' que podemos perceber no quadro de Belmiro, o desejo aparente de se submeter às leis visuais mais do que à pura e simples transcrição de uma realidade pré-existente ao quadro, revelam uma afinidade com uma certa sensibilidade subjetivista, comum na Europa finde-siècle. Esta faria com que os temas camponeses, aparentemente tão prosaicos, desempenhassem, paradoxalmente, um papel fundamemental em estilos artificiais e estetizantes ligados ao Simbolismo e a outras correntes pós-impressionistas. Bastaria lembrar aqui a importância dos temas campesinos nos quadros impregnados de alusões religiosas do já citado Segantini, mas também, nos de Vincent Van Gogh, de Paul Gauguin, dos Nabis Paul Sérusier e Émile Bernard, entre outros ${ }^{17}$.

A importância que as figurações do homem do campo passaram a ganhar na obra dos pintores brasileiros certamente se encontra relacionada com outros fenômenos que atravessavam a cultura européias da segunda metade do século XIX, como a voga das comunidades e colônias de artistas sediadas em centros rurais. Essa última tendência se difundiu por toda Europa, sendo até hoje famosas as comunidades de artistas então formadas na Bretanha, como a de PontAven, ou aquelas de Worpswede e Nau-Dechau, próximas de cidades alemãs como Bremen e Munique ${ }^{18}$. A despeito das variantes nacionais, alguns fatores comuns se encontravam na base da formação dessas comunidades artísticas rurais: para além das motivações mais prosaicas, como a difusão do hábito da pintura en plein air ou mesmo os aluguéis muito mais baixos no campo, foi sobretudo decisiva, nesse sentido, "a obsessão européia com o mito do camponês rural como uma figura de grande valor moral, não corrompido pela sofisticação e pelo materialismo do mundo urbano moderno" 19 .

Na primeira década do século XX, alguns artistas brasileiros de passagem pela Europa foram seduzidos por esse apelo do 'primitivo' e trocaram as grandes capitais pelas pequenos vilarejos interioranos. Caso típicos foram o alagoano Rosalvo Ribeiro e o do baiano Prisciliano Silva. Este último, por sinal, estava na França mais ou menos na mesma época em que Carlos Chambelland lá realizou a sua primeria estadia: após um período na Academia Julian, de Paris, onde teria sido discípulo de Adolphe Dechaneaud, Jules Lèfèbvre e Tony Robert-Fleury, Prisciliano viajou para a Bretanha, se estabelecendo na cidade de Concarneau, onde produziu uma considerável coleção de telas versando sobre a cultura camponesa $\operatorname{local}^{20}$. Depois de uma estadia no Brasil, o pintor retornaria à França em 1912, fixando-se novamente em Concarneau, até às vésperas da $1^{\text {a }}$ Guerra Mundial, sempre empenhado em registrar os pitorescos tipos e hábitos locais. 


\section{IMAGENS DO HOMEM RURAL - II: REPRESENTAÇÕES DO CAM- PONÊS BRASILEIRO}

Todo esse interesse pela representação do camponês europeu, testemunhado na pintura dos artistas brasileiros em estágio no Velho Mundo, conheceu uma transposição direta em nossa cultura figurativa. Ainda antes dos anos 1880, começaram a surgir quadros que faziam alusão aos tipos rurais nacionais. Uma das obras pioneiras nesse sentido foi O Derrubador Brasileiro, de José Ferraz de Almeida Júnior, terminado em 1879, quando o pintor ainda estagiava, como pensionista do Imperador D. Pedro II, em Paris. Esse quadro de Almeida Júnior só foi apresentado no Rio de Janeiro na Exposição Geral de 1884 e ainda que nele o pintor lance mão de citações calcadas no repertório da estatuária antiga e que caracterize o seu personagem com traços e com um vigor físico que remetem ao culto indianista, ainda muito comum ${ }^{21}$, a intenção de representar o típico brasileiro ligado à terra é patente.

Com a proclamação da República, em 1889, como já fizemos notar, a questão da identidade brasileira voltou a adquirir ares de urgência. Alguns quadros do pintor de origem espanhola Modesto Brocos y Gomez, como Engenho de Mandioca (1892) ou Redenção da Can (1895), fazem notar como os habitantes e os modos de vida rurais começavam a se impor como motivos privilegiados para atender à esse renovada demanda por símbolos nacionais. Redenção da Can é, nesse sentido, uma obra das mais interessante, pois nela a ambientação e as figuras camponesas adquirem uma conotação ainda mais ampla, uma vez que se encontram associadas ao difundido mito da origem do povo brasileiro como fruto da mistura das três raças fundadoras - o índio autóctone, o branco europeu e o negro africano. O título da tela é uma alusão ao tema bíblico de Can, um dos três filhos de Noé, que fora castigado pelo pai que impôs uma maldição a seu filho, Canaã, condenando-o a ser escravo dos tios e dos irmãos (Gênesis, 9). O título é já, portanto, um indicador do quanto a representação, sem rejeitar o realismo, se encontra impregnada de intenções alegóricas. No quadro de Brocos, a mãe, uma mulata - óbvia referência ao tipo da Virgem com o menino - se encontra ladeada pelo pai, um caipira, 'mistura' étnica de branco com índio, e pela avó negra, que ergue as mãos aos céus em sinal de agradecimento pela criança. Dessa maneira, ao mesmo tempo em que aponta para um inequívoco e desejado 'branqueamento da raça' deixando transparecer o seu vínculo com concepções eugenistas, às quais voltaremos a nos referir, Redenção da Can nos apresenta o nascimento de um brasileiro 'autêntico', fruto da miscigenação de várias raças, no contexto do ambiente rural brasileiro.

Outros pintores fluminenses igualmente se voltaram, nos anos 1890, para os temas rurais, em um movimento que foi claramente apoiado pela principal 
instituição de ensino artístico brasileiro de então, a Escola Nacional de Belas Artes. Só para sublinhar esse ponto, basta lembrar que pintores desde muito dedicados às representações de temas campesinos, como Henrique Bernardellli e Modesto Brocos, atuaram como professores da instituição desde o momento de sua reforma, após a proclamação da República. Em 1894, João Baptista da Costa, pintor que posteriormente se tornaria uma das mais importantes figuras da cena artística brasileira, conquistou, naquela que foi a primeira Exposição Geral de Belas Artes republicana, o prêmio máximo de Viagem ao Estrangeiro, justamente com a representação de um lavrador, o quadro intitulado Em Repouso, que pertence hoje ao acervo do MNBA-RJ.

Todavia, nos primeiros anos republicanos, foi mesmo o paulista Almeida Júnior quem realizou o esforço mais sistemático no sentido de fixar em imagens o camponês brasileiro. Após o seu regresso da Europa, Almeida Júnior voltou a se estabelecer em sua cidade natal, Itu, no interior do Estado de São Paulo. Lá, ele abriu um ateliê e deu início à produção de uma série de grandes composições regionalistas, que desde então se tornaram referências nacionais - Caipira picando fumo (1893), Amolação interrompida (1894), Cozinha caipira (1895), $O$ Violeiro (1899), etc. O sucesso de tais obras foi enorme, inclusive no Rio de Janeiro, e, nas décadas seguintes, elas seriam com frequiência citadas como os modelos por excelência de uma pintura autenticamente brasileira, em textos célebres de escritores como Monteiro Lobato ou Oswald de Andrade. No final do presente artigo, teremos oportunidade de voltar, com um pouco mais de vagar, às telas 'caipiras' de Almeida Júnior, aos discutirmos de que maneira algumas de suas características se encontram absorvidas nas obras 'sertanejas' de Carlos Chambelland.

\section{O SERTANEJO DE CARLOS CHAMBELLAND}

Depois de nossa digressão sobre a mais ampla tendência regionalista que permeou a cultura figurativa brasileira desde as últimas décadas do século XIX, cumpre voltarmos ao ponto de partida. Inseridas nessa tendência regionalista, as obras de Carlos Chambelland tratam de um tipo bastante especifico de homem do campo, o sertanejo. Se a escolha do pintor era aparentemente original no âmbito das artes plásticas, cumpre dizer que ela possuía precedentes óbvios na produção de alguns literatos, que, já na virada para o século XX, haviam procurado incorporar ao projeto de construção da unidade nacional o homem do sertão do Nordeste. Foi esse o caso de Afonso Arinos de Melo Franco, em coletâneas de contos como Pelo sertão (1898) ou Os jagunços (1898), e, especialmente, o de Euclides da Cunha (1902), no clássico Os Sertões. Em certa medida, o sertanejo era pensado por estes e outros autores como o 'cerne da nacionalidade', o 
depositário da esperança na criação de uma civilização brasileira autêntica. Logo, podemos postular que, para além da estadia em Pernambuco a qual nos referimos logo no início desse texto, contribuíram para as pinturas 'sertanejas' de Chambelland todo um conjunto de idéias e aspirações que circulavam nos meios intelectuais brasileiros. Porém, é ainda necessário salientar que nem todas as vozes da intelectualidade brasileira da Primeira República se levantaram em uníssono em favor do homem do campo como símbolo da nação. Não podemos esquecer que o período foi igualmente marcado por teorias como o racismo científico e o eugenismo, segundo as quais o processo de miscigenação, característico das civilizações americanas - e da brasileira, em particular - poderia conduzir à uma decadência social. A visão negativa sobre o mundo americano, bastante antiga, ganhou uma força renovada entre nossa intelectualidade oitocentista, sobretudo após a ampla divulgação que conheceram os depoimentos do casal Agassiz ou do Conde Artur de Gobineau. Era igualmente difundida a noção de que a mescla de raças 'inferiores' havia gerado um povo preguiçoso, indisciplinado e pouco inteligente. Nesse sentido, é bastante elucidativo lembrarmos que o já citado Monteiro Lobato, na primeira versão de seu célebre personagem Jeca Tatu, lançada ao público em 1914 em um artigo d'O Estado de S. Paulo, estava longe de louvar o trabalhador rural, mas, pelo contrário, caracterizou-o como obscurecido pela preguiça e inapto à civilização - em suma, como uma síntese das mazelas nacionais ${ }^{22}$. Lançando mão de cânones científicos então muito influntes, como a teoria da desigualdade inata das raças e o seu corolário, a já referida ideía de uma degeneração racial promovida pela miscigenação, Lobato fez o Jeca Tatu cair nas graças da elite letrada precisamente por traduzir em sua prosa a percepção negativa que esta tinha do povo brasileiro. Representações desse processo de degeneração racial nas artes são particularmente freqüentes em obras ligadas àquele movimento que se se convencionou chamar Naturalismo, bem exemplificado nos romances de Aluisio Azevedo ou Júlio Ribeiro, que perpassava nossa cultura desde finais do século XIX. A esse respeito comentou Jorge Coli:

\footnotetext{
Houve então a descoberta de um exotismo social próximo, em que se dramatizava a brutalidade popular. A literatura, o teatro e até mesmo a ópera viam-se tomados por situações de violência ocorridas na cidade ou no campo. Degustavam-se com prazer os impulsos meio cegos e aterradores atribuídos à falta de sofisticação mental dos protagonistas. ${ }^{23}$
}

Fazemos referência a esse clima 'naturalista', encontrado também na arte da pintura, porque algo dele está certamente presente em algumas obras do início da carreira de Carlos Chambelland, especialmente em seu espetacular quadro Final de jogo, datado de 1907, e que lhe valeu nada menos do o Prêmio de 
Viagem ao Estrangeiro na Exposição Nacional de Belas Artes daquele ano. No tema dramático - que retrata as conseqüências aparentemente fatais da briga em uma taverna entre figuras das classes mais humildes -, e na composição - a grande diagonal ascendente que parte do homem estendido no chão, à esquerda do quadro, até o agressor, à direita - Chambelland parecia fazer referência a uma tela do italiano Michelle Cammarano, Rissa a Trastereve (1886), provavelmente conhecida no meio artístico brasileiro por intermédio de artistas como Henrique Brenardelli e Modesto Brocos.

Lembrar Final de Jogo é aqui importante por dois motivos contrastantes. Por um lado, nessa obra relativamente precoce - Carlos Chambelland tinha apenas vinte e três anos quando a realizou -, pode-se perceber o interesse pelos personagens populares que, por sua condição social, são em tudo intercambiáveis com os sertanejos que o pintor posteriormente elegeria como motivos. Por outro lado, nada na concepção dramática da obra de 1907 deixa entrever o clima que iria imperar nas obras 'sertanejas' de Chambelland: nestas últimas, frutos de uma concepção estética certamente mais madura, se encontra ausente qualquer vontade de retratar os dramas ou os conflitos violentos relativos às figuras humildes que nelas figuram. É como se, entre as atitudes opostas de exaltação ou de condenação do camponês-sertanejo que vicejavam lado-a-lado nos meios intelectuais brasileiros, o pintor optasse por uma posição de eminente neutralidade. $\mathrm{Na}$ maior parte dos quadros que tivemos oportunidade de analisar, essa concepção particular de Chambelland a respeito do tema se manifesta principalmente através da maneira como os sertanejos são retratados e que impede que nós, espectadores, tenhamos acesso direto aos seus estados de espírito. Para criar tal efeito de distanciamento entre personagens e espectador, são empregados alguns recursos compositivos que gostaríamos de rapidamente enumerar, comentando algumas obras do pintor. Um desses recursos recursos de que se vale Chambelland é megulhar seus sertanejos em um estado de aparente introspecção. Isso é evidente já em obras nas quais as figuras são mostrados em close e um bom exemplo disso pode ser encontrado em um quadro de datação imprecisa intitulado Vaqueiro. O rosto de perfil guarda o frescor de um esboço rapidamente executado e é pintado com pinceladas largas, carregadas de tinta espessa. Mas, como que contrastando com essa fatura franca, a expressão do personagem é das mais reservadas. Sereno, aparentemente absorvido em contemplação, com sua cabeça emoldurada pelo chapéu de couro cujo desenho arredondado parece remeter ao de uma auréola, o vaqueiro abaixa os olhos e evita estabelecer qualquer contato mais íntimo com o espectador - traço significativo, que se repete em outros quadros de Chambelland que comentaremos a seguir. 
Em alguns outros quadros de Chambelland, como Cozinha de interior ou Engenho de cana, o total alheamento com relação ao espectador que caracteriza o Vaqueiro se encontra acentuado, de maneira quase literal, pelas inserção dos personagens em amplos espaços: a escala relativamente diminuta que as figuras adquirem em tais pinturas faz com que elas pareçam se encontrar afastadas do primeiro plano. Por seu turno, esse distanciamento sugerido pela perspectiva se soma ao outro já referido, que poderíamos qualificar de 'psicológico', pois, mais uma vez, a maneira como os personagens são representados não permite que aquele que os observa tenha qualquer acesso aos seus estados de ânimo. O efeito é semelhante àquele encontrado em algumas obras de Almeida Júnior, como na já citada Cozinha Caipira ou, ainda, em Apertando o Lombilho (1895). O estatuto ambíguo dessas imagens do pintor ituano também parece se refletir nas duas obras de Chambelland: se o ambiente obscuro figurado em $\mathrm{Co}$ zinha de interior parece ecoar o recolhimento da mulher que nele trabalha, contribuindo para um clima de relativa intimidade, poderíamos de igual maneira postular, como fez Rodrigo Naves a respeito da 'cozinha' de Almeida Júnior, que esse mesmo ambiente tem "mais o aspecto de um covil do que de uma habitação humana" 24 . Em Engenho de cana, por sua vez, os dois trabalhadores, absorvidos na atividade que foi por muito tempo identificada como a principal fonte de riqueza da região nordestina, agem sem deixar transparecer nenhum afeto: será que eles conferem ao seu trabalho o caráter sacro de uma espécie de ritual ou são simplesmente autômatos, alienados de seus árduos afezeres?

Mais complexo é o quadro de Chambelland que reproduzimos logo no início do artigo, Volta do trabalho. Atrás do lavrador em primeiro plano, que carrega nos ombros uma enxada, quatro outras figuras, representadas dos quadris para cima, se encontram dispostas em fila, paralelamente à superfície da obra, cuja concepção se aproxima assim da de um friso escultórico antigo. As duas figuras na porção direita da obra são caracterizadas de um modo que lembra muito o acima referido Vaqueiro: elas parecem não se dar conta da existência do espectador e embora estejam retornando para casa - como o título da obra indica -, após um dia presumivelmente extenuante na lavoura, são representadas com um ar carregado de dignidade e mesmo de certa altivez.

Mas é nos três personagens representados na porção esquerda da obra que a atitude de alheamento dos sertanejos é representada da maneira mais espetacular, como que no próprio ato de sua manifestação. Esse ato se inicia na justaposição dos rostos dos dois lavradores ligeiramente deslocados do centro do quadro. Pela sua relativa semelhança - os dois ostentam o mesmo tipo bigode, de barba rala e de chapéu, os dois fumam o mesmo tipo de cigarro - esses rostos podem ser interpretados como a síntese de duas fases de uma espécie de movi- 
mento estroboscópico unitário, o de se voltar para encarar o espectador. Tal justaposição reforça, assim, a impressão de que o lavrador no primeiro plano literalmente acabou de se virar e agora nos fita de uma maneira desconfiada. Esse gesto parece ser, todavia, menos uma tentativa de estabelecer qualquer tipo de comunicação do que a interposição de uma barreira. A maneira como o sertanejo segura a enxada, como se de um lanceiro se tratasse, reforça a postura de reserva que se desenha em sua fisionomia, uma vez que a ferramenta, cortando a extensão do quadro em diagonal, se configura como um obstáculo a qualquer maior aproximação. Se o sertanejo acabou de se dar conta de nossa presença, estranha ao seu mundo, ele imediatamente procura resguardar a sua privacidade e integridade. O referido movimento de se voltar para encarar o espectador, encarnado na justaposição das duas cabeçcas no centro do quadro, pode então ser lido em um sentido inverso: agora, o lavrador desvia o seu olhar do espectador. A última fase desse ato de alheamento é eloquentemente representada pela figura na extrema esquerda, que, trajando uma indumentária semelhante a do personagem no primeiro plano e também segurando uma enxada, nos dá as costas e se afasta, desviando-se para 'dentro' do quadro.

Parecem ter sido múltiplas as fontes de inspiração que levaram Chambelland a plasmar essa sua particular caracterização do homem dos sertões. Por um lado, ela nos faz recordar alguns artistas europeus seus contemporâneos, como aqueles ligados às tendências da cultura figurativa francesa que, transitando entre naturalismo, simbolismo, ideal moral e engajamento social, marcaram os Salons parisienses a partir dos anos 1880. Nesse sentido, é digna de nota as relações entre a obra de Chambelland e a de pintores da chamada École de Nancy, como P.-A. Dagnan-Bouveret ou Henri Royer, muito ligados às comunidades rurais de artistas na Bretanha ${ }^{25}$. A abordagem que estes pintores faziam das tradições regionais e da vida contemporânea fora da capital francesa se encontra, de fato, bastante afinizada com os interesses de Chambelland. Isso se evidencia quando observamos algumas telas de Royer, como L'ex-voto (1897) ou La Bénédicite (1898), cuja fatura pictórica e cujos personagens, estáticos, como que fechados sob si mesmos, remetem aos quadros de Chambelland. Mesmo que este não tenha estudado diretamente com Royer - cujo quadro Sur la butte, de 1891, foi, inclusive, adquirido pela Escola Nacional de Belas Artes -, é pouco provável que não tenha se sentido atraído pela obra de um artista que, pouco antes da sua chegada à Paris, havia sido professor de seu irmão Rodolpho e participava ativamente do salão da Société Nationale des Beaux-Arts.

Outra referência importante, essa já por nós adiantada, é a obra de Almeida Júnior. Poderíamos mesmo dizer que, na simplicidade e na aparente neutralidade de seus quadros, Chambelland como que tentava emular aquilo que, algu- 
mas décadas antes, Almeida Júnior havia conseguido realizar abordando o caipira paulista, ou seja, aprofundar a questão da presumida essência do homem brasileiro, evitando deliberadamente conferir-lhe um aspecto heróico. Nas pinturas de Chambelland, o sertanejo, assim como o caipira de Almeida Júnior, expressa a sua maneira de ser no mundo na sua própria atitude de preservação - uma tese já proposta por Jorge Coli em artigo sobre o pintor ituano já citado. A indiferença ou reserva do homem do sertão com relação aquele que de fora o observa seria, nesse sentido, uma espécie de tradução em seus gestos, em suas postura, da sua própria natureza psicológica, imune às seduções do mundo urbano.

Essa idéia nos leva de volta a um outro artista já citado, dessa vez não um pintor, mas um literato: Euclides da Cunha. Não teria o célebre autor dos Sertões postulado que fora justamente o isolamento o fator que conferira ao sertanejo, "o ser híbrido formado sob o sol dos sertões interiores da terra [...], uma feição própria, distinta e positiva" ${ }^{26}$ Em uma conhecida passagem de seu livro mais famoso, Euclides da Cunha tece as seguintes considerações:

Porque ali ficaram, inteiramente divorciados do resto do Brasil e do mundo, murados a leste pela Serra Geral, tolhidos no ocidente pelos amplos campos gerais, que se desatam para o Piauí e que ainda hoje o sertanejo acredita sem fins.

O meio atraía-os e guardava-os.

As estradas de um e outro lado da meridiana, impróprias à dispersão, facilitavam antes o entrelaçamento dos extremos do país. Ligavam-nos no espaço e no tempo. Estabelecendo no interior a contigüidade de povoamento, que faltava ainda em parte na costa, $[\ldots]$ aquela rude sociedade, incompreendida e olvidada, era o cerne vigoroso da nossa nacionalidade. ${ }^{27}$

O isolamento referido por Euclides da Cunha é, certamente, um isolamento geográfico, cujas reações conferiram à "raça forte e antiga" dos sertanejos "caracteres definidos e imutáveis mesmo nas maiores crises - quando a roupa de couro do vaqueiro se faz a armadura flexível do jagunço [...] um caráter de originalidade completa expresso mesmo nas fundações que erigiu" ${ }^{\prime 2}$. Nas telas de Chambelland que analisamos, esse isolamento que decorre do meio físico parece encontrar um eco formal no acentuado despojamento que caracteriza os cenários que circundam os sertanejos, por vezes nada mais do que um fundo obscuro ou vazio de referências.

Todavia, como adiantamos, o isolamento do homem do sertão se reflete nesses quadros, de um modo ainda mais fundamental, na própria atitude psicológica que ostenta. Mergulhando seus sertanejos em um estado de mudo solipsis- 
Chambelland

mo, Carlos Chambelland parece ter tentado capturar justamente a suposta essência dos mesmos, reservada e conservadora - essência essa que lhes permitiu reter justamente o que, nas primeiras décadas da República, foi julgado por muitos como o que de mais autêntico restava da cultura brasileira.

Recebido em 19 de junho de 2008

\section{NOTAS}

1 "N a intimidade dos nossos artistas". In: O Jornal, p.17, Rio de Janeiro, 22 de agosto 1926.

${ }^{2}$ COSTA, Angyone. A inquietação das abelhas (O que dizem nossos pintores, escultores, arquitetos e gravadores, sobre as artes plásticas no Brasil). Rio de Janeiro: Pimenta de Mello \& Cia, 1927, p.145. Disponível em: http://www.dezenovevinte.net/artigos_imprensa/artigos_ac.htm. Acesso em: 01 mar. 2008.

${ }^{3}$ Idem, p.146.

${ }^{4}$ LEITE, José R. T. D icionário Crítico da Pintura no Brasil. Rio de Janeiro: Artlivre, 1988, p.118.

${ }^{5}$ COSTA, op. cit, p.146.

${ }^{6}$ Carlos Chambelland viajou a primeira vez para a Europa logo após ter conquistado o Prêmio de Viagem ao Estrangeiro na Exposição Geral de Belas Artes de 1907, com a tela Final de Jogo. D urante cerca de dois anos, ele fixou-se em Paris, onde teria freqüentado o ateliê de pintor francês Eugene Carrière, além de academias livres, como a célebre Academia Julian.

${ }^{7}$ N. "Exposição Chambelland". In: Revista do Brasil, p.541-542, São Paulo, dez. 1917.

${ }^{8}$ CH IARELLI, Domingos Tadeu. Um Jeca nas Vernissages: Monteiro Lobato e o D esejo de uma Arte $N$ acional no Brasil. São Paulo: EDU SP, 1995, p.93sg. N esse sentido, vale lembrar que, como crítico de arte da Revista do Brasil em sua primeira fase, pontificava ninguém menos do que Monteiro Lobato, célebre defensor da identidade e das riquezas brasileiras

${ }^{9}$ M ARQ U ES, L. (org.). 30 Mestres da Pintura no Brasil. São Paulo: MASP / R. de Janeiro: M N BA, 2001, p.120.

${ }^{10}$ SCH W ARCZ, Lilia M oritz. As barbas do imperador: Dom Pedro II, um monarca nos trópicos. Sãp Paulo: Companhia das Letras, 1998, p.148.

${ }^{11}$ MIG LIACCIO, Luciano. "Rodolfo Amoedo. 0 mestre, deveríamos acrescentar". 19\&20 - A revista eletrônica de DezenoveVinte, Rio de Janeiro, abr. 2007, vol. II, n. 2. Disponível em: http:// www.dezeno vevinte. net/artistas/ra migliaccio.htm. Acesso em: 01 mar. 2008.

${ }^{12} \mathrm{C}$ omo disse com ironia $\mathrm{H}$ enri Meñdras: "Exaltar a simplicidade da vida rústica, a grandeza do trabalho encarniçado, a beleza das mãos calejadas, o significado profundo da terra e da natureza, a ligação visceral à gleba, o respeito à auto ridade patriarcal e divina, etc., é bastante aprazível para autores que passaram suas vidas conversando em luxuosos salões envoltos por parques bem aparados e talhados" - MED RAS, Henri. So ciétés Paysanes: Eléments pour une théorie de la paysanerie. Librarsie Armand Colin: Paris, 1976, p.161.

${ }^{13}$ BRETTEL, Richard \& Caroline. Les peintres et le paysan au XIXe Siècle. Edition d'Art Albert Skira: Geneve, 1983, p.14

${ }^{14}$ O s Brettell observam que "O Salon de 1831 marca o apogeu da pintura clássica de gênero camponês na França, as imagens mais importantes de Robert, Schnetz, H audebourt-Lescot e H orace Vernet ali estavam expostas" (Idem, p.16). 
15 "Justamente porque os $\mathrm{N}$ azarenos e os pintores que trabalham sobre o seu influxo evitam em seu Purismo de ceder às tentações do pitoresco e da pintura de gênero, todos os elementos realísticos de suas figurações são o fruto de uma real observação in situ e são realizados com uma precisão digna de ilustrações científicas" (M ET KEN apud CO LI, Jorge. A Batalha de Guararapes de Victor Meirelles e suas relações com a pintura internacional. C ampinas, Tese de Livre-D ocência em H istória da Arte, IFCH UN IC AMP, 1997, p.196-197)

${ }^{16}$ Idem, p.198

17 Sobre esse tópico, conferir o breve apanhado presente no capítulo "AU DÉLÀ DU REALISME: L'image du paysan à la fin du XIX e siècle. 1880-1900". In: BRETTELL, op. cit., p.44-55.

${ }^{18}$ PERRY, G ill. 0 Primitivismo e o "Moderno". In: HARRISO N , Charles [et alli]. Primitivismo, Cubismo, Abstração. São Paulo: Cosac \& N aify, 1998, p.8-15 e p.34-45

19 Idem, p.10.

${ }^{20}$ GAN TO IS, Ana M aria D 'Errico. "U m estudo sobre Prisciliano Silva”. Revista O hun - Revista eletrônica do Programa de Pós-Graduação em Artes Visuais da Escola de Belas Artes da U FBA, Salvador, Ano 2, out. 2005, n.2. Disponível em: http://www.revistao hun.ufba.br/html/artigo 1n2.html. Acesso em: 01 mar. 2008.

${ }^{21} \mathrm{~N} 0$ esboço feito pelo próprio Almeida Junior para o Catálogo llustrado da Exposição de 1884, 0 Derrubador Brasileiro aparece significativamente com um outro título, Índio no Repouso.

${ }^{22}$ Sob a influência do movimento higienista de Belisário Penna e Miguel Pereira, Monteiro Lobato mudaria radicalmente a sua o pinião a respeito do caipira; conferir ALVES FILHO, Aluizio. As metamorfoses do Jeca Tatu: A questão da identidade do brasileiro em Monteiro Lobato. Rio de Janeiro: Inverta, 2003.

${ }^{23}$ C O LI, Jorge. "A violência e o caipira". In: Estudos Históricos, Arte e História, n.30, p.6, São Paulo, $2002 / 2$.

${ }^{24}$ N AVES, Rodrigo. Almeida Júnior: "O sol no meio do caminho". In: Novos Estudos, n.73, p.141, São Paulo, nov. 2005.

${ }^{25}$ L 'école de $N$ ancy: peinture et art nouveau. Paris: Éditions de la Réunion des M usées N ationaux, 1999.

26 O LIVEIRA, Ricardo de. "Euclides da Cunha, O s Sertões e a invenção de um Brasil profundo". In: Revista Brasileira de História, vol.22, n.44, p.523, São Paulo, 2002,

${ }^{27}$ CUN HA apud O LIVEIRA, op. cit, p.524

${ }^{28}$ CUN HA apud O LIVEIRA, op. cit, p.524. 